\title{
HIV Viral Load Suppression in Adults and Children Receiving Antiretroviral Therapy-Results From the leDEA Collaboration
}

\author{
Awachana Jiamsakul, PhD, * Azar Kariminia, PhD, * Keri N. Althoff, PhD, $†$ Carina Cesar, MD, $\neq$ \\ Claudia P. Cortes, MD, § Mary-Ann Davies, MBChB,\| Viet Chau Do, MD, $\mid$ Brian Eley, MBChB,\# \\ John Gill, MBChB, ** Nagalingeswaran Kumarasamy, MD, $+\dagger$ Daisy Maria Machado, MD, $\neq$ \\ Richard Moore, MD, $\S \S$ Hans Prozesky, MMed(Int), ||| Elizabeth Zaniewski, MS, 99 and \\ Matthew Law, PhD*
}

\begin{abstract}
Background: Having $90 \%$ of patients on antiretroviral therapy (ART) and achieving an undetectable viral load (VL) is 1 of the 90:90:90 by 2020 targets. In this global analysis, we investigated the proportions of adult and paediatric patients with VL suppression in the first 3 years after ART initiation.
\end{abstract}

Methods: Patients from the IeDEA cohorts who initiated ART between 2010 and 2014 were included. Proportions with VL suppression $(<1000$ copies $/ \mathrm{mL})$ were estimated using (1) strict intention to treat (ITT)-loss to follow-up (LTFU) and dead patients counted as having detectable VL; and (2) modified ITT-LTFU and dead patients were excluded. Logistic regression was used to identify predictors of viral suppression at 1 year after ART initiation using modified ITT.

Results: A total of 35,561 adults from 38 sites/16 countries and 2601 children from 18 sites/6 countries were included. When comparing strict with modified ITT methods, the proportion achieving VL suppression at 3 years from ART initiation changed from $45.1 \%$ to $90.2 \%$ in adults, and $60.6 \%$ to $80.4 \%$ in children. In adults, older age, higher CD4 count preART, and homosexual/bisexual HIV exposure were associated with VL suppression. In children, older age and higher CD4 percentage pre-ART showed significant associations with VL suppression.

Received for publication November 14, 2016; accepted June 12, 2017.

From the *The Kirby Institute, UNSW, Sydney, New South Wales, Australia; $†$ Department of Epidemiology, Johns Hopkins Bloomberg School of Public Health, Baltimore, MD; \$Fundacion Huesped, Buenos Aires, Argentina; §University of Chile School of Medicine \& Fundación Arriaran, Santiago, Chile; ||School of Public Health and Family Medicine, University of Cape Town, Cape Town, South Africa; 9 Children’s Hospital 2, Ho Chi Minh City, Vietnam; \#Department of Paediatrics and Child Health, University of Cape Town, Cape Town, South Africa; **University of Calgary, Calgary, Alberta, Canada; ††YRGCARE Medical Centre, Chennai, India; +†Pediatric Infectious Disease Division, Escola Paulista de Medicina-Universidade Federal de SãoPaulo, São Paulo, Brazil; §§Division of Infectious Diseases, Department of Medicine, Johns Hopkins University, Baltimore, MD; |||Division of Infectious Diseases, Department of Medicine, University of Stellenbosch and Tygerberg Hospital, Cape Town, South Africa; and 9 IInstitute of Social and Preventive Medicine, University of Bern, Bern, Switzerland.

Supported by the U.S. National Institutes of Health's National Institute of Allergy and Infectious Diseases, the Eunice Kennedy Shriver National Institute of Child Health and Human Development, and the National Cancer Institute under the following award numbers by region-Asia-Pacific: U01AI069907; Caribbean, Central and South America (CCASAnet): U01AI069923; Southern Africa: U01AI069924; and North America (NA-ACCORD): U01AI069918, F31DA037788，G12MD007583，K01AI093197，K23EY013707，K24DA000432，K24AI065298，KL2TR000421，M01RR000052，N02CP055504, P30AI027757, P30AI027763, P30AI027767, P30AI036219, P30AI050410, P30AI094189, P30AI110527, P30MH62246, R01AA016893, R01CA165937，R01DA004334，R01DA011602，R01DA012568，R24AI067039，U01AA013566，U01AA020790, U01AI031834, U01AI034989, U01AI034993, U01AI034994, U01AI035004, U01AI035039, U01AI035040, U01AI035041, U01AI035042, U01AI037613, U01AI037984, U01AI038855, U01AI038858, U01AI042590, U01AI068634, U01AI068636, U01AI069432, U01AI069434, U01AI103390, U01AI103397, U01AI103401, U01AI103408, U01DA036935, U01HD032632, U10EY008057, U10EY008052, U10EY008067, U24AA020794, U54MD007587, UL1RR024131, UL1TR000004, UL1TR000083, UL1TR000454, UM1AI035043, Z01CP010214, and Z01CP010176; contracts: CDC-200-2006-18797 and CDC-200-2015-63931 from the Centers for Disease Control and Prevention, USA; contract 90047713 from the Agency for Healthcare Research and Quality, USA; and contract 90051652 from the Health Resources and Services Administration, USA; grants: CBR-86906, CBR-94036, HCP-97105, and TGF-96118 from the Canadian Institutes of Health Research, Canada; Ontario Ministry of Health and Long Term Care; and the Government of Alberta, Canada. Additional support was provided to NA-ACCORD by the Intramural Research Program of the National Cancer Institute. The Kirby Institute is funded by the Australian Government Department of Health and Ageing, and is affiliated with the Faculty of Medicine, UNSW Sydney (The University of New South Wales).

Oral presentation: The Australasian HIV\&AIDS Conference; November 17, 2016; Adelaide, South Australia, Australia. Abstract: 124.

The funders had no role in study design, data collection and analysis, decision to publish, or preparation of the manuscript. The content is solely the responsibility of the authors and does not necessarily represent the official views of any of the governments or institutions mentioned above.

A.J. and A.K. are equal first authors.

The authors have no conflicts of interest to disclose.

Supplemental digital content is available for this article. Direct URL citations appear in the printed text and are provided in the HTML and PDF versions of this article on the journal's Web site (www.jaids.com).

Correspondence to: Awachana Jiamsakul, PhD, The Kirby Institute, UNSW, Sydney, New South Wales 2052, Australia (e-mail: ajiamsakul@kirby.unsw.edu. au).

Copyright (C) 2017 Wolters Kluwer Health, Inc. All rights reserved. 
Conclusions: Large increases in the proportion of VL suppression in adults were observed when we excluded those who were LTFU or had died. The increases were less pronounced in children. Greater emphasis should be made to minimize LTFU and maximize patient retention in HIV-infected patients of all age groups.

Key Words: HIV, suppression, paediatrics, adults, IeDEA

(J Acquir Immune Defic Syndr 2017;76:319-329)

\section{INTRODUCTION}

Durable virologic suppression is the primary goal of antiretroviral therapy (ART). Having $90 \%$ of patients on ART with undetectable HIV viral load (VL) is the third " 90 " for global programs as part of the 90:90:90 targets. ${ }^{1}$ Increasingly, VL testing is offered as part of ART monitoring to confirm early treatment failure and to indicate second-line treatment switch to reduce the accumulation of HIV drug resistance mutations. The World Health Organization (WHO) now recommends routine $\mathrm{VL}$ testing ${ }^{2}$ as the preferred method to detect ART failure rather than immunological and clinical monitoring.

The International Epidemiology Databases to Evaluate AIDS (IeDEA) global consortium was established by the U.S. National Institute of Allergy and Infectious Diseases in 2005. There are 7 regional data centers within IeDEA in North America (The North American AIDS Cohort Collaboration on Research and Design, NA-ACCORD), the Caribbean, Central and South America (CCASAnet), the Asia-Pacific (AP), and Africa (East Africa, EA; Central Africa, CA; West Africa, WA; Southern Africa, SnA). ${ }^{3,4}$ Currently, IeDEA includes data on more than 1 million people living with HIV/ AIDS. According to individual country assessments ${ }^{5}$ on HIV indicators for sites within NA-ACCORD and CCASAnet, the percentage of patients on ART in the United States was 67\%, whereas the highest was reported for Mexico at $90 \%$. In the African population, in particular EA and SnA, ART coverage increased from $24 \%$ in 2010 to $54 \%$ in 2015 , whereas CA and WA had a lower percentage coverage at $28 \%$. ART usage in AP doubled from $19 \%$ in 2010 to $41 \%$ in $2015 .^{6}$ The proportion of patients with VL suppression across different IeDEA regions in recent years, however, remains unclear. The primary objective of this study was to estimate the proportions of adult and paediatric patients enrolled in IeDEA, who achieved undetectable VL in the first 3 years after initiating ART. The secondary objective was to determine factors associated with VL suppression at 1 year after ART.

\section{METHODS}

\section{Study Population and Inclusion Criteria}

Adult and paediatric patients enrolled in IeDEA were included if they had initiated ART between 2010 and 2014 . Paediatric patients were defined as children and adolescents aged 18 years and younger when starting ART; adults were those aged 18 years and older at ART initiation. ART was defined as 3 or more antiretroviral drugs in a single regimen;

320 | www.jaids.com those who started treatment with mono- or dual-drug regimens were excluded. Sites within each respective participating region were included if they were confirmed to perform routine annual VL testing. If no specific information was provided regarding VL testing frequency, we performed a calculation by obtaining the average number of VL tests for each patient from the regional cohort enrolment date to the last follow-up date. If the median number of VL tests per patient per site was above 0.8 , that site was included in the initial data capture. However, only patients with at least $1 \mathrm{VL}$ test after ART initiation were included in the analyses.

\section{Definitions}

VL suppression was defined as VL $<1000$ copies $/ \mathrm{mL}$ at 1,2 , and 3 years from ART initiation to be consistent with the WHO definition for classifying virological failure. ${ }^{2}$ Moreover, because of the use of different virological assays across the regions with varying lower limits of detection, the use of this threshold of VL $<1000$ copies $/ \mathrm{mL}$ allowed the inclusion of sites with higher undetectable cutoffs. This threshold also removed the concern of unnecessarily excluding patients experiencing transient virological "blips" and then returning to virologic suppression." The annual time points reflect the WHO recommendations for VL testing to monitor for treatment failure. ${ }^{8}$ We have chosen to include data up to 3 years after ART initiation to minimize loss to follow-up (LTFU), as patient retention has been shown to decrease to $65 \%$ at 3 years. ${ }^{9}$ As different sites have different definitions of LTFU, patients in this study were considered to be LTFU according to the LTFU indicator provided in each regional database. If no LTFU information was available, patients who were not seen within 6 months ${ }^{10}$ before the database closing date were considered lost at their final visit date defined as the latest of $\mathrm{CD} 4, \mathrm{VL}$, or clinic visit date.

\section{Statistical Analyses}

Simple proportions were calculated by percentages. Two methods were used to estimate proportions of patients with undetectable VL.

\section{Strict Intention to Treat}

Patients who were LTFU or dead were counted as having detectable VL after their last visit/death date up until 3 years after ART initiation. Patients who were transferred out were removed from the analyses after their transfer date. The denominator for each 1-, 2-, and 3- year time point included patients who had VL testing at that time point and patients who were LTFU or dead before that time point (counted as having detectable VL). Patients who did not have VL testing or transferred out before each time point were not included in the denominator (Supplemental Digital Content Figs. 1 and 3, http://links.lww.com/QAI/B64).

\section{Modified Intention to Treat}

The denominator at each time point included patients who had VL testing at that time point. Patients who did not have VL testing, or those who were LTFU, dead, or 
transferred out before each time point were not included in the denominator (Supplemental Digital Content Fig. 2, http:// links.lww.com/QAI/B64).

Factors associated with VL suppression at 1 year, as defined by the modified intention-to-treat (ITT) method, were analyzed using logistic regression methods. We chose to analyze VL suppression at 1 year to minimize LTFU cases. In addition, as we included the VL measurement closest to the annual time point, our analyses would not be biased by how often VL was assessed. Covariates included were age at ART initiation, sex, previous AIDS diagnosis, pre-ART CD4 count or percent, HIV mode of exposure, and region. ART combinations were not included in the analyses because of potential collinearity with different regions. For example, we would expect to see most patients from resource-limited regions, such as in Asia and Africa, initiating on a nucleoside reverse transcriptase inhibitors and a non-nucleoside reverse transcriptase inhibitors combination, whereas protease inhibitor-based and integrase inhibitor-based regimens would be most commonly used in developed countries such as those in NA-ACCORD. All variables were entered in the multivariable model; no model selection was attempted. $P$ values $<0.05$ were considered statistically significant. Sensitivity analyses were performed using the strict ITT definition, as well as using VL failure as the outcome of interest, defined as $\mathrm{VL} \geq 1000$ copies $/ \mathrm{mL}$.

Each regional data center was responsible for ethics approval, development of data collection systems, extracting data from their regional database or requesting relevant data variables from designated programs within their region, and verifying data quality. The data sets were then centrally aggregated and analyzed at The Kirby Institute, UNSW Sydney (the University of New South Wales), Australia, the regional data center of the IeDEA AP region. All data management and statistical analyses were performed using SAS software version 9.4 (SAS Institute Inc., Cary, NC) or Stata software version 14 (Stata Corp., College Station, TX).

\section{RESULTS}

\section{Adults}

There were a total of 38 sites from 16 countries: 12 sites/8 countries from AP, 6 sites $/ 5$ countries from CCASAnet, 14 sites/2 countries from NA-ACCORD, and 6 sites from South Africa (SA), a country within the IeDEA SnA regional cohort that met the eligibility criteria for adult analyses. Median VL testing frequency for each site ranged from 0.9 to 4.2 per patient per year. A total of 35,561 patients were included in the analyses: $2121(6.0 \%)$ from AP; 3404 (9.6\%) from CCASAnet; 14,579 (41.0\%) from NA-ACCORD; and 15,457 (43.5\%) from SA (Table 1 and Supplemental Digital Content Table 5, http://links.lww.com/ QAI/B64). Sixty-one percent were men. At ART initiation, the median age was 37 years [interquartile range (IQR 30-46 years)] and the median CD4 cell count was 218 cells $/ \mu \mathrm{L}$ (IQR: $105-344$ cells $/ \mu \mathrm{L}$ ).

Using the strict ITT method, the overall proportion of adults with VL suppression at 1 year from ART initiation was
TABLE 1. Patient Characteristics

\begin{tabular}{|c|c|c|}
\hline & $\begin{array}{c}\text { Total Adults: } \\
\mathbf{3 5 , 5 6 1}\end{array}$ & $\begin{array}{l}\text { Total Children: } \\
2601\end{array}$ \\
\hline & Number* (\%) & Number* (\%) \\
\hline $\begin{array}{l}\text { Median age at ART initiation } \\
\text { (yrs) }\end{array}$ & 37 (IQR 30-46) & $\begin{array}{l}4.65 \\
\text { (IQR } 1.02-9.75)\end{array}$ \\
\hline \multicolumn{3}{|l|}{ Sex } \\
\hline Male & $21,623(60.8)$ & 1299 (49.9) \\
\hline Female & $13,935(39.2)$ & $1302(50.1)$ \\
\hline Unknown & $3(0.0)$ & $0(0.0)$ \\
\hline \multicolumn{3}{|l|}{ Previous AIDS-defining illness } \\
\hline No & $15,508(43.6)$ & $164(6.3)$ \\
\hline Yes & $2695(7.6)$ & $52(2.0)$ \\
\hline Unknown & $17,358(48.8)$ & $2385(91.7)$ \\
\hline Median pre-ART CD4 count & $\begin{array}{l}218 \text { cells } / \mu \mathrm{L} \\
\text { (IQR } 105-344)\end{array}$ & $\begin{array}{c}15.89 \% \\
\text { (IQR } 8.70-23.24)\end{array}$ \\
\hline \multicolumn{3}{|l|}{ HIV mode of exposure } \\
\hline Homosexual/bisexual & $8537(24.0)$ & $0(0.0)$ \\
\hline Heterosexual & $14,216(40.0)$ & $0(0.0)$ \\
\hline IDU & $1639(4.6)$ & $0(0.0)$ \\
\hline Perinatal & $0(0.0)$ & $2119(81.5)$ \\
\hline Otheri & $645(1.8)$ & $190(7.3)$ \\
\hline Unknown & $10,524(29.6)$ & $292(11.2)$ \\
\hline \multicolumn{3}{|l|}{ Region } \\
\hline Asia-Pacific & $2121(6.0)$ & $291(11.2)$ \\
\hline $\begin{array}{l}\text { Caribbean, Central and South } \\
\text { America }\end{array}$ & $3404(9.6)$ & $75(2.9)$ \\
\hline North America & $14,579(41.0)$ & $0(0.0)$ \\
\hline South Africa & $15,457(43.5)$ & $2235(85.9)$ \\
\hline
\end{tabular}

*Unless otherwise specified.

$\dagger$ †For children, "Other" includes sexual behaviour (184), sexual abuse (2), blood transfusion (2), and breastfeeding (2).

IDU, injecting drug users.

$83.0 \% ; 70.0 \%$ at 2 years; and $45.1 \%$ at 3 years. Figure $1 \mathrm{~A}$ shows the proportions of adults with VL suppression decreasing after 2 years for NA-ACCORD and SA, with AP maintaining the highest VL suppression over the full 3 years. Using the modified ITT method where patients who were LTFU or dead were excluded, of the 35,561 adults patients, 26,153 (73.5\%) had VL testing at 1 year; 13,602 $(38.2 \%)$ at 2 years; and $4629(13.0 \%)$ at 3 years. Overall, VL suppression increased to $88.5 \%, 89.5 \%$, and $90.2 \%$ for years $1-3$, with all regions showing high proportions above $85 \%$ for all years (Fig. 1B).

Table 2 shows factors associated with VL suppression at 1 year using the modified ITT method. The multivariate results show that after adjustment for all variables, sex was the only factor showing no association with VL suppression $(P=0.358)$. The odds for VL suppression increased with age 25-49 years [odds ratio $(\mathrm{OR})=1.42,95 \%$ confidence interval (CI): 1.24 to 1.63 ], and age 50 years and older $(\mathrm{OR}=2.20$, $95 \%$ CI: 1.86 to 2.60 ), all $P<0.001$, compared with age 24 years and younger. Pre-ART CD4 count also showed an increasing trend: $200-349$ cells $/ \mu \mathrm{L}(\mathrm{OR}=1.60,95 \% \mathrm{CI}: 1.44$ to 1.78$), 350-499$ cells $/ \mu \mathrm{L}(\mathrm{OR}=1.73,95 \% \mathrm{CI}: 1.48$ to $2.02)$, and $\geq 500$ cells $/ \mu \mathrm{L}(\mathrm{OR}=1.91,95 \% \mathrm{CI}: 1.62$ to 2.26$)$, all $P<0.001$, compared with $\mathrm{CD} 4<200$ cells $/ \mu \mathrm{L}$. Patients 
FIGURE 1. Proportion of adults with viral load (VL) suppression using $(A)$ strict intention-to-treat and (B) modified intention-to-treat methods. CCASAnet, Caribbean, Central, and South America; VL, viral load.

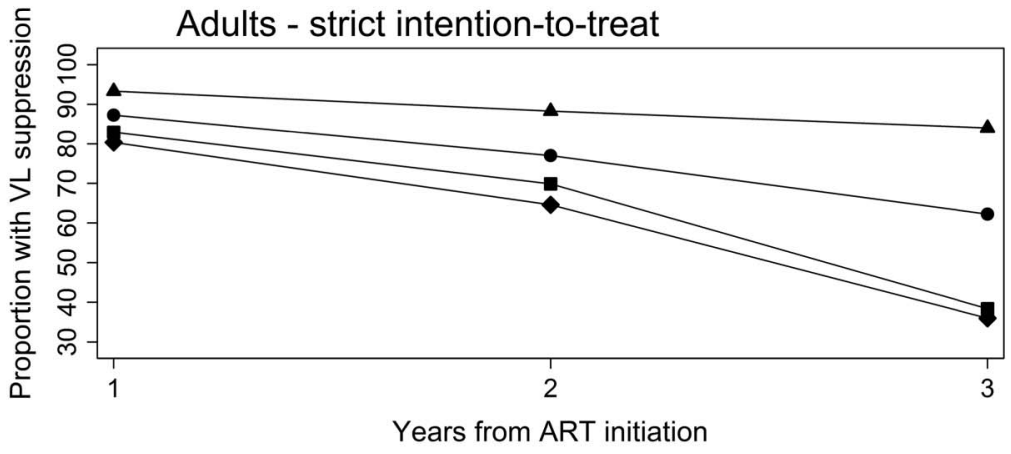

Total patients Asia-Pacific CCASAnet North America 1842 2918 11677 South Africa 11441
1358

2097

6884

7041
920

1240

3223 3872
A

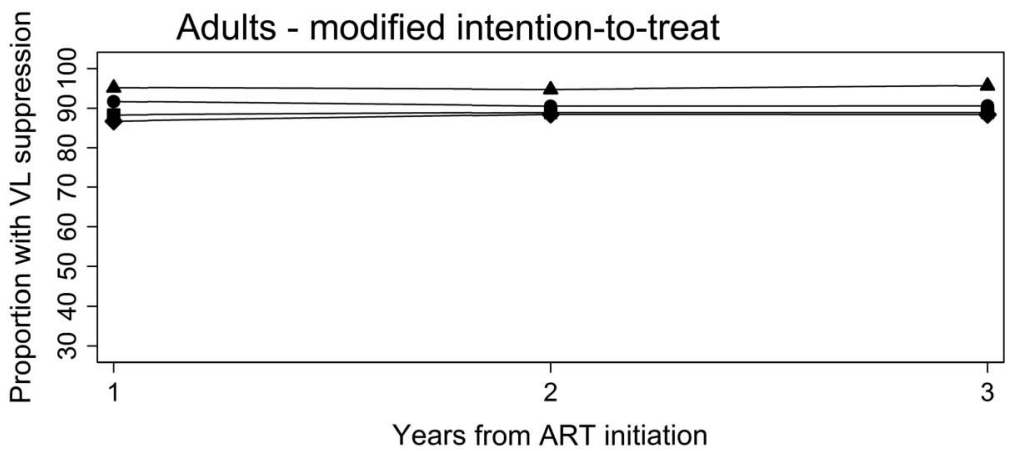

Total patients Asia-Pacific CCASAnet

North America South Africa 1806 2777 10970

B

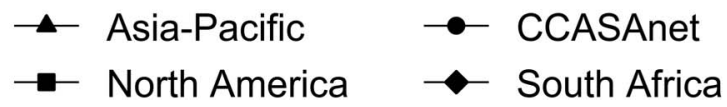

with homosexual/bisexual mode of HIV exposure were more likely to have VL suppression $(\mathrm{OR}=1.66,95 \% \mathrm{CI}$ : 1.46 to $1.89, P<0.001)$, whereas injecting drug users had reduced odds compared with heterosexual mode of exposure $(\mathrm{OR}=$ $0.69,95 \%$ CI: 0.58 to $0.83, P<0.001)$. Having a previous AIDS-defining illness also negatively affected VL response $(\mathrm{OR}=0.82,95 \% \mathrm{CI}$ : 0.71 to $0.95, P=0.008)$. Comparison of different regions showed that when compared with NAACCORD, AP $(\mathrm{OR}=2.78,95 \% \mathrm{CI}: 2.2$ to $3.52, P<0.001)$ and CCASAnet $(\mathrm{OR}=1.70,95 \% \mathrm{CI}: 1.45$ to $2.00, P<$ 0.001 ) had higher proportions of VL suppression. When AP was the reference group, patients in CCASAnet $(\mathrm{OR}=0.61$, 95\% CI: 0.47 to $0.79, P<0.001)$; NA-ACCORD (OR $=$ $0.36,95 \%$ CI: 0.28 to $0.45, P<0.001)$; and SA (OR $=0.37$, 95\% CI: 0.29 to $0.48, P<0.001$ ), had smaller proportions of patients with VL suppression. Additional tests for multi-

\section{2 | www.jaids.com}

collinearity showed that there was no collinearity among the variables included.

\section{Paediatrics}

The paediatric analysis included 18 clinical centers from 3 IeDEA regions with 2601 children overall: 291 $(11.2 \%)$ from 10 AP sites/3 countries, 75 (2.9\%) from 4 CCASAnet sites/ 2 countries, and 2235 (85.9\%) from 4 sites in SA (Table 1 and Supplemental Digital Content Table 6, http://links.lww.com/QAI/B64). Median VL testing frequency for each site ranged from 1.5 to 2.7 per patient per year. At ART initiation, the median age was 4.7 years (IQR 1.0-9.8). For 1677 children with available data, the median CD4 percentage was 15.9 (IQR 8.70-23.24) with 477 $(18.3 \%)$ children having CD4 percentage $<10 \%$. A small

Copyright (C) 2017 Wolters Kluwer Health, Inc. All rights reserved. 
TABLE 2. Factors Associated With Viral Load Suppression at 1 Year From ART Initiation, Adult Analysis Using Modified Intentionto-Treat Method $(\mathrm{N}=26,153)$

\begin{tabular}{|c|c|c|c|c|c|c|c|c|}
\hline & \multirow[b]{2}{*}{ Total Patients } & \multirow{2}{*}{$\begin{array}{l}\mathrm{VL}<1000 \\
\text { Copies } / \mathrm{mL}\end{array}$} & \multicolumn{3}{|c|}{ Univariate } & \multicolumn{3}{|c|}{ Multivariate } \\
\hline & & & OR & $95 \% \mathrm{CI}$ & $P$ & OR & $95 \% \mathrm{CI}$ & $P$ \\
\hline Age at ART initiation (yrs) & & & & & $<0.001$ & & & $<\mathbf{0 . 0 0 1}$ \\
\hline $18-24$ & 2065 & 1773 & Ref & & & Ref & & \\
\hline $25-49$ & 19,275 & 16,974 & 1.21 & 1.07 to 1.39 & 0.004 & 1.42 & 1.24 to 1.63 & $<\mathbf{0 . 0 0 1}$ \\
\hline$\geq 50$ & 4813 & 4393 & 1.72 & 1.47 to 2.02 & $<0.001$ & 2.20 & 1.86 to 2.60 & $<\mathbf{0 . 0 0 1}$ \\
\hline \multicolumn{9}{|l|}{ Sex } \\
\hline Male & 16,323 & 14,565 & Ref & & & Ref & & \\
\hline Female & 9828 & 8573 & 0.82 & 0.76 to 0.89 & $<0.001$ & 1.04 & 0.95 to 1.14 & 0.358 \\
\hline Unknown & 2 & 2 & & & & & & \\
\hline Previous AIDS-defining illness & & & & & 0.027 & & & 0.008 \\
\hline No & 11,027 & 9705 & Ref & & & Ref & & \\
\hline Yes & 2000 & 1725 & 0.85 & 0.74 to 0.98 & 0.027 & 0.82 & 0.71 to 0.95 & 0.008 \\
\hline Unknown & 13,126 & 11,710 & 1.13 & 1.04 to 1.22 & 0.003 & 0.83 & 0.69 to 0.99 & 0.036 \\
\hline Pre-ART CD4 count (cells/ $\mu \mathrm{L})$ & & & & & $<0.001$ & & & $<0.001$ \\
\hline$<200$ & 10,000 & 8590 & Ref & & & Ref & & \\
\hline $200-349$ & 6241 & 5661 & 1.60 & 1.45 to 1.77 & $<0.001$ & 1.60 & 1.44 to 1.78 & $<\mathbf{0 . 0 0 1}$ \\
\hline $350-499$ & 2631 & 2393 & 1.65 & 1.43 to 1.91 & $<0.001$ & 1.73 & 1.48 to 2.02 & $<\mathbf{0 . 0 0 1}$ \\
\hline$\geq 500$ & 2363 & 2160 & 1.75 & 1.50 to 2.04 & $<0.001$ & 1.91 & 1.62 to 2.26 & $<\mathbf{0 . 0 0 1}$ \\
\hline Missing & 4918 & 4336 & 1.22 & 1.10 to 1.36 & $<0.001$ & 1.29 & 1.16 to 1.44 & $<\mathbf{0 . 0 0 1}$ \\
\hline HIV mode of exposure & & & & & $<0.001$ & & & $<\mathbf{0 . 0 0 1}$ \\
\hline Homosexual/bisexual & 6676 & 6139 & 1.73 & 1.56 to 1.92 & $<0.001$ & 1.66 & 1.46 to 1.89 & $<\mathbf{0 . 0 0 1}$ \\
\hline Heterosexual & 10,403 & 9036 & Ref & & & Ref & & \\
\hline IDU & 1229 & 1017 & 0.73 & 0.62 to 0.85 & $<0.001$ & 0.69 & 0.58 to 0.83 & $<\mathbf{0 . 0 0 1}$ \\
\hline Other & 504 & 449 & 1.24 & 0.93 to 1.64 & 0.148 & 1.10 & 0.82 to 1.48 & 0.534 \\
\hline Unknown & 7341 & 6499 & 1.17 & 1.07 to 1.28 & 0.001 & 1.23 & 1.12 to 1.36 & $<\mathbf{0 . 0 0 1}$ \\
\hline Region & & & & & $<0.001$ & & & $<\mathbf{0 . 0 0 1}$ \\
\hline Asia-Pacific & 1806 & 1719 & 0.38 & 0.31 to 0.48 & $<0.001$ & 2.78 & 2.20 to 3.52 & $<\mathbf{0 . 0 0 1}$ \\
\hline Caribbean, Central and South America & 2777 & 2546 & 0.68 & 0.59 to 0.79 & $<0.001$ & 1.70 & 1.45 to 2.00 & $<0.001$ \\
\hline North America & 10,970 & 9685 & Ref & & & Ref & & \\
\hline South Africa & 10,600 & 9190 & 1.16 & 1.07 to 1.25 & $<0.001$ & 1.03 & 0.85 to 1.25 & 0.767 \\
\hline
\end{tabular}

proportion (0.2) had experienced WHO clinical stage 4 events before ART initiation. These baseline patient characteristics differed between regions. Median CD4 percentage and age were $12 \%$ and 8 years in AP, $23 \%$ and 11 years in CCASAnet, and $16 \%$ and 4 years in SA.

Using strict ITT methods as shown in Figure 2A, a decrease in the proportion of children with VL $<1000$ copies/mL over time was seen for CCASAnet $(80.3 \%$ at year $1,68.3 \%$ at year 2 and $50.0 \%$ at year 3 ) and SA regions $(73.3 \%-67.5 \%$ and $56.7 \%)$. Using the modified ITT approach, CCASAnet still showed a decline in the proportion of children with viral suppression from $81.7 \%$ to $73.7 \%$, and $69.2 \%$ for years $1-3$. Overall, during the follow-up period, $69.2 \%-83.0 \%$ of children maintained VL $<1000$ copies $/ \mathrm{mL}$ (Fig. 2B).

The adjusted statistical analysis (Table 3) identified the following baseline characteristics to be associated with VL suppression at 1 year after ART initiation: age 1.5-4 years $(\mathrm{OR}=2.33,95 \% \mathrm{CI}: 1.73$ to $3.14, P<0.001)$; 5-9 years $(\mathrm{OR}=2.79,95 \% \mathrm{CI}: 2.06$ to $3.78, P<0.001) ; 10-14$ years $(\mathrm{OR}=2.32,95 \% \mathrm{CI}: 1.70$ to $3.16, P<0.001)$; and $15-17$ years $(\mathrm{OR}=2.34,95 \% \mathrm{CI}: 1.28$ to $4.27, P=0.006)$ compared with children younger than 1.5 years (the reference group); and pre-ART CD4 percentage 15\%-24\% $(\mathrm{OR}=2.38,95 \% \mathrm{CI}: 1.67$ to $3.41, P<0.001)$ and $\geq 25 \%$ $(\mathrm{OR}=1.81,95 \% \mathrm{CI}: 1.24$ to $2.64, P=0.002)$ versus $\mathrm{CD} 4$ $<10 \%$. Other factors, including sex, WHO clinical stage 4 , mode of exposure, and region were not significantly associated with VL suppression. No collinearity was detected among the variables.

The strict ITT sensitivity analyses (Supplemental Digital Content Tables 1 and 2, http://links.lww.com/ QAI/B64) showed similar results to the main analyses. In VL failure analyses (Supplemental Digital Content Tables 3 and 4, http://links.lww.com/QAI/B64), the ORs of the covariates were simply the reciprocal of the ORs reported in the main analyses, with the same $P$-values. This indicates that the use of logistic regression was appropriate for both VL suppression and VL failure outcomes in adults and children. 
FIGURE 2. Proportion of paediatric patients with viral load (VL) suppression using $(A)$ strict intention-to-treat and (B) modified intention-to-treat methods. CCASAnet, Caribbean, Central, and South America; VL, viral load.

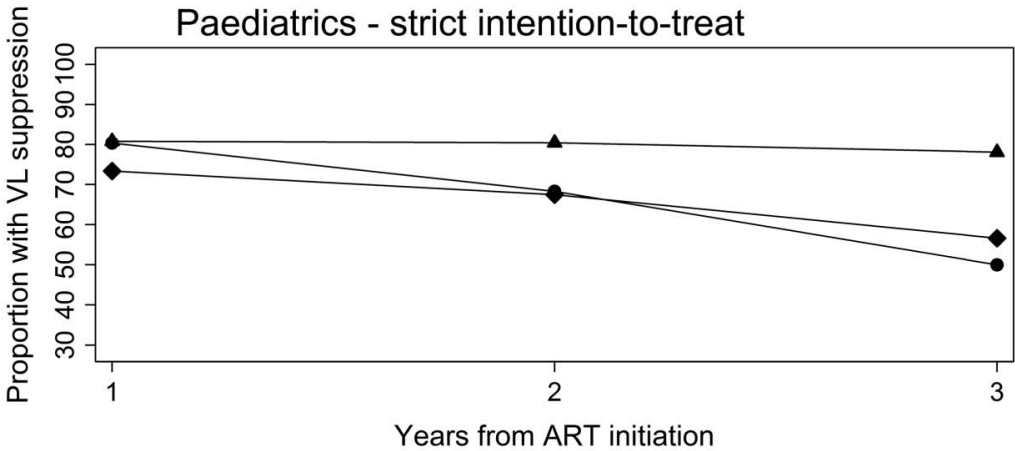

Total patients Asia-Pacific CCASAnet

\section{A}

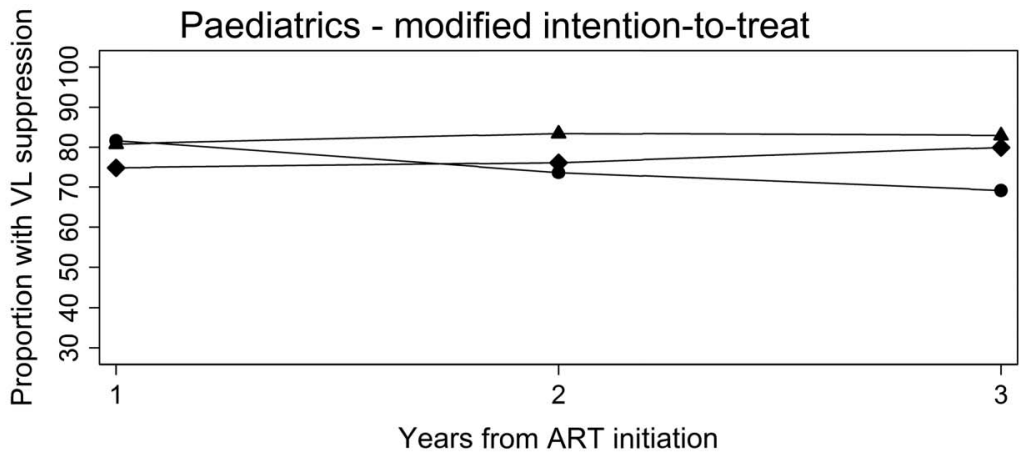

Total patients Asia-Pacific CCASAnet

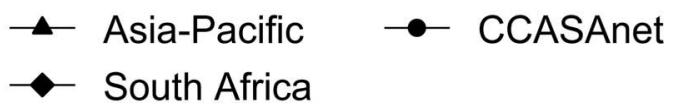

\section{DISCUSSION}

Our study included data from 4 IeDEA regions covering 35,561 patients from 38 adult sites and 2601 patients from 24 paediatric sites who initiated ART between 2010 and 2014. Using the modified ITT approach that excludes LTFU and those who died, the proportions of patients with VL suppression was $90 \%$ for adults and $80 \%$ for children at 3 years. However, when the strict ITT approach was used, including LTFU and deceased patients and categorizing them as having detectable VL, these estimates decreased to $45 \%$ in adults and $61 \%$ in children. In adults, older age, higher pre-ART CD4 count, homosexual/bisexual and other modes of HIV exposure were associated with a better chance of achieving VL suppression at 1 year from ART initiation. Children older than 1.5 years and CD4 $\geq 15 \%$ were associated with a higher chance of achieving VL suppression.
Adults from the AP region performed significantly better than other regions. In children, VL suppression at 1 year did not differ significantly between regions.

Patients included in this study were those from sites that offered routine annual VL testing. Many resource-limited countries throughout the world currently do not offer routine VL tests for the detection of HIV treatment failure. For example, all sites within the WA, CA, and EA IeDEA regions and countries within the SnA IeDEA region outside SA did not have annual VL testing for the 2010-2014 time period. Some countries in the AP region, including Cambodia and Vietnam, also did not perform routine VL testing. The $\mathrm{WHO}^{2}$ guidelines have recently recommended that VL testing be the preferred method of detecting treatment failure, and many countries have adopted this recommendation and are scaling-up their VL monitoring capacity. ${ }^{11,12}$ Studies have

Copyright (C) 2017 Wolters Kluwer Health, Inc. All rights reserved. 
TABLE 3. Factors Associated With Viral Suppression at 1 Year From ART Initiation, Paediatric Analysis Using Modified Intention to Treat Method $(\mathrm{N}=1968)$

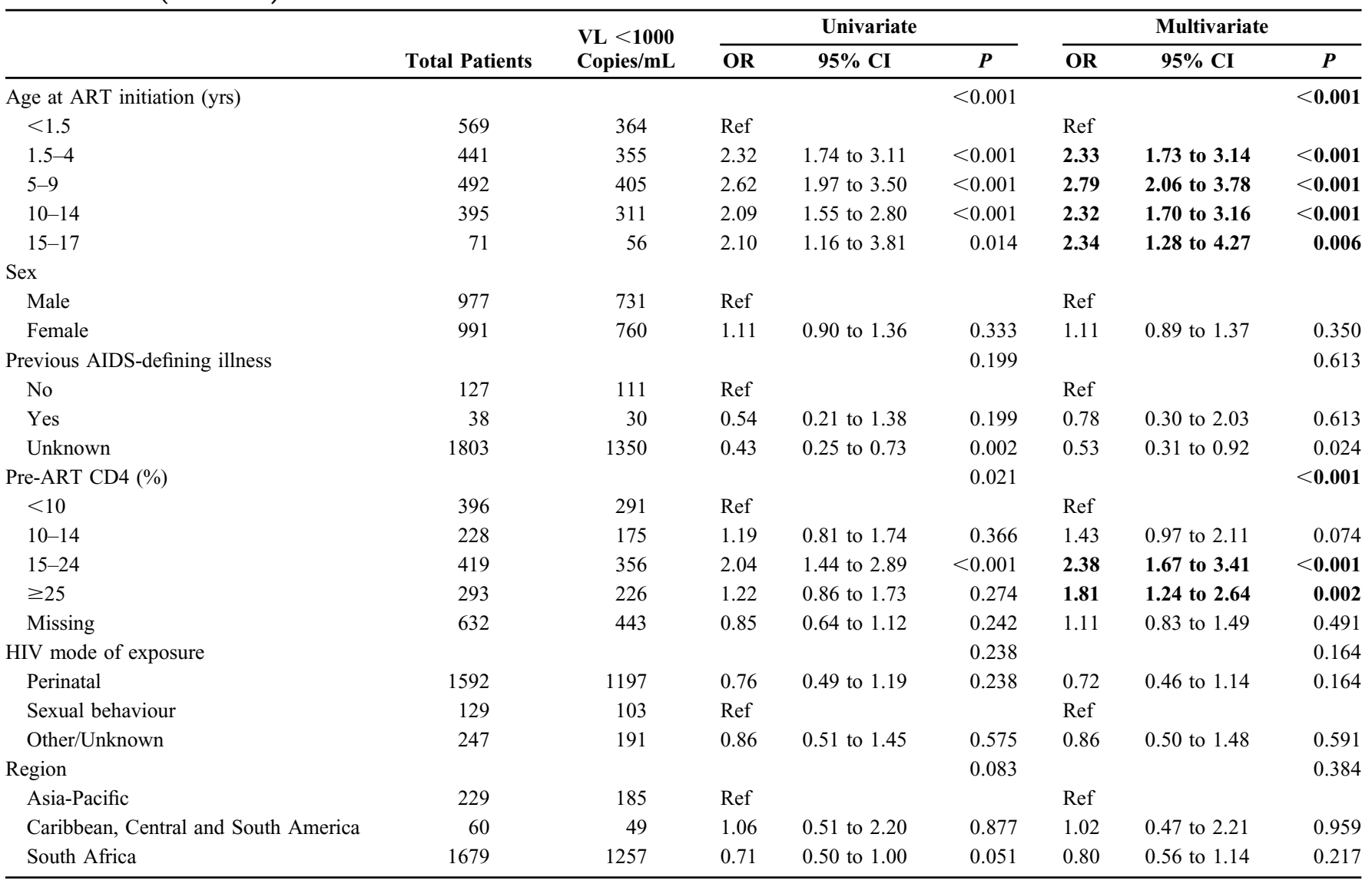

Values in bold represent significant covariates in the adjusted model.

shown that the WHO's immunologic and clinical failure criteria have performed poorly in predicting virological treatment failure leading to unnecessary switch to second-line ART during periods of VL suppression, or delayed switch because of the misclassification of treatment failure. ${ }^{13-15}$ Using CD4 monitoring in the presence of HIV drug resistance, mutations during periods of viraemia may also lead to delayed ART switches compared with VL monitoring alone. ${ }^{16}$ Delayed second-line ART switch can lead to the accumulation of drugresistant mutations, ${ }^{17,18}$ which can compromise treatment options for second-line therapy, particularly in resourcelimited countries. In addition, low positive predictive value of current immunological criteria may result in increased costs because of unnecessary switches to second-line therapy in people with adequate VL suppression. ${ }^{14}$ Unfortunately, some countries that do not yet offer VL monitoring continue to refer to CD4 measurements and clinical monitoring in the assessment of HIV treatment outcomes.

The overall high proportions of VL suppression under the modified ITT analyses indicate that patients who are followed-up and retained in care have a good response to treatment. This is in contrast to the decrease in the proportion of adults and children achieving VL suppression when LTFU and dead patients were included as being detectable under strict ITT methods. The decrease in the proportion of patients with VL suppression was less pronounced in children. When compared with adults, children had higher rates of suppression when we considered LTFU and death as detectable. This might be explained by a lower rate of LTFU in children $(6 \%)$ compared with adults $(12 \%)$ in this study. The decrease in VL suppression when patients who were LTFU or dead were assumed to have detectable viraemia has also been reported in another study, ${ }^{19}$ which suggests the importance of retention in HIV care. Mortality rates were often found to be higher in children and adults who were LTFU or transferred out compared with patients who were retained in care. ${ }^{20,21}$ An Australian study, however, showed no association between LTFU and mortality, possibly because of unreported reengagement into care. ${ }^{22}$

The multivariate analyses in this study indicate that the adult AP cohort has performed significantly better than NAACCORD as well as other cohorts, although proportions of VL suppression were above $85 \%$ for all regions. These results most likely reflect the patient recruitment process within AP. Sites in AP are urban referral centres and patients were recruited based on the likelihood of remaining in care. ${ }^{23}$ 
These results therefore do not represent the general HIVinfected population in Asia, and should be interpreted with caution. In contrast, for children the chance of VL suppression did not differ across regions which may indicate less between-region heterogeneity and less variations in both patient-level and site-specific factors. High clinical resources and access to paediatric antiretroviral formulations were reported in a survey of paediatric HIV programmatic and clinical management practices in Asia and sub-Saharan Africa. ${ }^{24}$

The association between older age and higher pre-ART CD4 count with VL suppression, and the increased risk of VL failure in patients with injecting drug users mode of exposure and those who had a previous AIDS-defining illness in adults are consistent with other published literature. ${ }^{19,25-27}$ Although homosexual mode of exposure is often associated with lower adherence levels leading to poorer treatment outcomes, ${ }^{28}$ the positive effect of this transmission group could possibly be explained by better ART adherence levels reported in some patients. ${ }^{29-31} \mathrm{We}$ found that children who initiated ART when CD4 $>10 \%$ and those who started at 1.5 years of age were more likely to achieve VL suppression. This may reflect the impact of early access to ART and higher baseline level of RNA in infants and young children. An early study conducted in America found that infants whose disease progressed rapidly have high numbers of HIV-1 RNA copies during the first 24 months of life. ${ }^{32}$ The association between high baseline VL $(>1$ million copies $/ \mathrm{mL})$ and VL failure has been also reported by a more recent study conducted in children in SA. ${ }^{33}$ In addition, adherence issues related to taste and formulation, dosing and/or high pharmacokinetic variability of drugs might adversely affect virological response and contribute to poorer responses in younger children. ${ }^{34}$

Our study has several limitations including the classification of LTFU and dead patients as having detectable VL. Classifying dead patients as virological failure is debatable in terms of 90:90:90 and treatment as prevention. However, we have used this definition to be consistent with that used in clinical trials where LTFU and dead patients would generally be classified as "failed." It is also consistent with a strict ITT approach which includes all patients. Known transferred cases were excluded from the calculations, but there may be instances where patients have self-transferred without the knowledge of the treating physician. Patients in follow-up without VL testing were also not included in our analyses. This could be considered a potential bias as targeted VL testing to confirm treatment failure often occurs in resourcelimited settings. However, as our study only included sites with annual VL testing, we assume that the bias caused by targeted VL testing would be minimized. Last, the lack of data completeness and heterogeneity of treatment approaches and settings are another concern when analyzing large collaborative data set. There may be discrepancies between the actual last follow-up date and the final visit date calculated using our definition which could lead to misclassifications of LTFU patients. Furthermore, $86 \%$ of children in this study are from SA, therefore the generalizability of our paediatric findings is limited. Data on ART adherence and factors related to ART adherence such as disclosure and orphan

326 | www.jaids.com status in children were not available in our data set and therefore were not included in the multivariate analyses. As adherence level is a known predictor of virological outcomes $^{35}$ and disclosure in children is associated with ART adherence, ${ }^{36}$ our analysis results should be interpreted with this in mind.

\section{CONCLUSIONS}

This multiregional collaborative study showed that a high level of VL suppression can be achieved among children and adults receiving ART in resource-limited settings. Our findings highlight that even for those retained in care, achieving 90:90:90 for children may be more challenging. Sustainable approaches are needed to ensure optimal clinical outcomes and to minimize LTFU and increase patient retention.

\section{ACKNOWLEDGMENTS}

The authors thank all patients and their families, and all staff at participating sites for preparation of data contributed to this collaborative work. The authors also thank the IeDEA-WHO Collaboration for their guidance and expertise.

The TREAT Asia HIV Observational Database (TAHOD): P.S. Ly (TAHOD Steering Committee member) and $V$. Khol, National Center for HIVIAIDS, Dermatology \& STDs, Phnom Penh, Cambodia; F.J. Zhang (TAHOD Steering Committee member), H.X. Zhao and N. Han, Beijing Ditan Hospital, Capital Medical University, Beijing, China; M.P. Lee (TAHOD Steering Committee member, Steering Committee Chair), P.C.K. Li, W. Lam, and Y.T. Chan, Queen Elizabeth Hospital, Hong Kong, China; N. Kumarasamy (TAHOD Steering Committee member), S. Saghayam, and C. Ezhilarasi, Chennai Antiviral Research and Treatment Clinical Research Site (CART CRS), YRGCARE Medical Centre, VHS, Chennai, India; S. Pujari (TAHOD Steering Committee member), K. Joshi, S. Gaikwad, and A. Chitalikar, Institute of Infectious Diseases, Pune, India; T.P. Merati (TAHOD Steering Committee member), D.N. Wirawan, and $F$. Yuliana, Faculty of Medicine Udayana University \& Sanglah Hospital, Bali, Indonesia; E. Yunihastuti (TAHOD Steering Committee member), D. Imran, and A. Widhani, Working Group on AIDS Faculty of Medicine, University of Indonesia/Cipto Mangunkusumo Hospital, Jakarta, Indonesia; S. Oka (TAHOD Steering Committee member), J. Tanuma, and T. Nishijima, National Center for Global Health and Medicine, Tokyo, Japan; J.Y. Choi (TAHOD Steering Committee member), S. Na, and J.M. Kim, Division of Infectious Diseases, Department of Internal Medicine, Yonsei University College of Medicine, Seoul, South Korea; B.L.H. Sim (TAHOD Steering Committee member), Y.M. Gani, and R. David, Hospital Sungai Buloh, Sungai Buloh, Malaysia; A. Kamarulzaman (TAHOD Steering Committee member), S.F. Syed Omar, S. Ponnampalavanar, and I. Azwa, University Malaya Medical Centre, Kuala Lumpur, Malaysia; R. Ditangco (TAHOD Steering Committee member), E. Uy, and R. Bantique, Research Institute for Tropical 
Medicine, Manila, Philippines; W.W. Wong (TAHOD Steering Committee member, co-Chair), W.W. Ku, and P.C. Wu, Taipei Veterans General Hospital, Taipei, Taiwan; O.T. Ng (TAHOD Steering Committee member), P.L. Lim, L.S. Lee, and R. Martinez-Vega, Tan Tock Seng Hospital, Singapore; P. Phanuphak (TAHOD Steering Committee member), $K$. Ruxrungtham, A. Avihingsanon, and C. Phadungphon, HIVNAT/Thai Red Cross AIDS Research Centre, Bangkok, Thailand; S. Kiertiburanakul (TAHOD Steering Committee member), S. Sungkanuparph, L. Chumla, and N. Sanmeema, Faculty of Medicine Ramathibodi Hospital, Mahidol University, Bangkok, Thailand; R. Chaiwarith (TAHOD Steering Committee member), T. Sirisanthana, W. Kotarathititum, and J. Praparattanapan, Research Institute for Health Sciences, Chiang Mai, Thailand; P. Kantipong (TAHOD Steering Committee member) and P. Kambua, Chiangrai Prachanukroh Hospital, Chiang Rai, Thailand; K.V. Nguyen (TAHOD Steering Committee member), H.V. Bui, DTH Nguyen, and D. T. Nguyen, National Hospital for Tropical Diseases, Hanoi, Vietnam; T.T. Pham (TAHOD Steering Committee member), D.D. Cuong, and H.L. Ha, Bach Mai Hospital, Hanoi, Vietnam; A.H. Sohn (TAHOD Steering Committee member), J.L. Ross (TAHOD Steering Committee member), and B. Petersen, TREAT Asia, amfAR-The Foundation for AIDS Research, Bangkok, Thailand; D.A. Cooper, M.G. Law (TAHOD Steering Committee member), A. Jiamsakul (TAHOD Steering Committee member), and D.C. Boettiger, The Kirby Institute, UNSW Sydney, Australia. The TREAT Asia Pediatric HIV Network (TApHOD): P.S. Ly (TApHOD Steering Committee member) and V. Khol, National Centre for HIVIAIDS, Dermatology and STDs, Phnom Penh, Cambodia; J. Tucker, New Hope for Cambodian Children, Phnom Penh, Cambodia; N. Kumarasamy (TApHOD Steering Committee member), S. Saghayam, and E. Chandrasekaran, YRGCARE Medical Centre, CART CRS, Chennai, India; D. K. Wati (TApHOD Steering Committee member), L.P.P. Atmikasari, and I.Y. Malino, Sanglah Hospital, Udayana University, Bali, Indonesia; N. Kurniati (TApHOD Steering Committee member) and D. Muktiarti, Cipto Mangunkusumo General Hospital, Jakarta, Indonesia; S.M. Fong (TApHOD Steering Committee member, Current Steering Committee), M. Lim, and F. Daut, Hospital Likas, Kota Kinabalu, Malaysia; N.K. Nik Yusoff (TApHOD Steering Committee member), and P. Mohamad, Hospital Raja Perempuan Zainab II, Kelantan, Malaysia; K.A. Razali (TApHOD Steering Committee member), T.J. Mohamed, and N.A.D.R. Mohammed, Pediatric Institute, Hospital Kuala Lumpur, Kuala Lumpur, Malaysia; R. Nallusamy (TApHOD Steering Committee member) and K.C. Chan, Penang Hospital, Penang, Malaysia; T. Sudjaritruk (TApHOD Steering Committee member), $V$. Sirisanthana, L. Aurpibul, and $P$. Oberdorfer, Department of Pediatrics, Faculty of Medicine, Chiang Mai University and Research Institute for Health Sciences, Chiang Mai, Thailand; R. Hansudewechakul (TApHOD Steering Committee member), S. Denjanta, W. Srisuk, and A. Kongphonoi, Chiangrai Prachanukroh Hospital, Chiang Rai, Thailand; P. Lumbiganon (TApHOD Steering Committee member, co-Chair), P. Kosalaraksa, P. Tharnprisan, and T. Udomphanit, Division of Infectious Diseases, Depart- ment of Pediatrics, Faculty of Medicine, Khon Kaen University, Khon Kaen, Thailand; G. Jourdain, PHPT-IRD UMI 174 (Institut de recherche pour le développement and Chiang Mai University), Chiang Mai, Thailand; T. Bunupuradah (TApHOD Steering Committee member), T. Puthanakit, W. Prasitsuebsai, and C. Phadungphon, HIV-NAT, The Thai Red Cross AIDS Research Centre, Bangkok, Thailand; K. Chokephaibulkit (TApHOD Steering Committee member), K. Lapphra, W. Phongsamart, and S. Sricharoenchai, Department of Pediatrics, Faculty of Medicine Siriraj Hospital, Mahidol University, Bangkok, Thailand; K.H. Truong (TApHOD Steering Committee member), Q.T. Du, and C.H. Nguyen, Children's Hospital 1, Ho Chi Minh City, Vietnam; V.C. Do (TApHOD Steering Committee member), T.M. Ha, and V.T. An, Children's Hospital 2, Ho Chi Minh City, Vietnam; L.V. Nguyen (TApHOD Steering Committee member), D.T.K. Khu, A.N. Pham, and L.T. Nguyen, National Hospital of Pediatrics, Hanoi, Vietnam; O.N. Le, Worldwide Orphans Foundation, Ho Chi Minh City, Vietnam; A.H. Sohn (TApHOD Steering Committee member), J.L. Ross, and C. Sethaputra, TREAT Asia/amfAR - The Foundation for AIDS Research, Bangkok, Thailand; D.A. Cooper, M.G. Law (TApHOD Steering Committee member), and A. Kariminia, The Kirby Institute, UNSW Sydney, Australia. IeDEA Caribbean, Central, and South America (CCASAnet): Fundación Huésped and Hospital Fernández, Argentina: Pedro Cahn, Carina Cesar, Valeria Fink, Omar Sued, Emanuel Dell'Isola, Hector Perez, Jose Valiente, Cleyton Yamamoto; Instituto Nacional de Infectologia Evandro Chagas-Fiocruz, Brazil: Beatriz Grinsztejn, Valdilea Veloso, Paula Luz, Raquel de Boni, Sandra Cardoso Wagner, Ruth Friedman, Ronaldo Moreira; Universidade Federal de Minas Gerais, Brazil: Jorge Pinto, Flavia Ferreira, Marcelle Maia; Universidade Federal de São Paulo, Brazil: Regina Célia de Menezes Succi, Daisy Maria Machado, Aida de Fátima Barbosa Gouvêa; Fundación Arriarán, Chile: Marcelo Wolff, Claudia Cortes, Maria Fernanda Rodriguez, Gladys Allendes; Les Centres GHESKIO, Haiti: Jean William Pape, Vanessa Rouzier, Adias Marcelin, Christian Perodin; Hospital Escuela Universitario, Honduras: Marco Tulio Luque; Instituto Hondureño de Seguridad Social, Honduras: Denis Padgett; Instituto Nacional de Ciencias Médicas y Nutrición Salvador Zubirán, Mexico: Juan Sierra Madero, Brenda Crabtree Ramirez, Paco Belaunzaran, Yanink Caro Vega; Instituto de Medicina Tropical Alexander von Humboldt, Peru: Eduardo Gotuzzo, Fernando Mejia, Gabriela Carriquiry; Vanderbilt University Data Center, USA: Catherine C. McGowan, Bryan E. Shepherd, Timothy Sterling, Karu Jayathilake, Anna K. Person, Peter Rebeiro, Mark Giganti, Jessica Castilho, Stephany N. Duda, Hilary Vansell, Fernanda Maruri. NAACCORD Collaborating Cohorts and Representatives: Adult AIDS Clinical Trials Group Longitudinal Linked Randomized Trials: Constance A. Benson and Ronald J. Bosch; AIDS Link to the IntraVenous Experience: Gregory D. Kirk; Fenway Health HIV Cohort: Stephen Boswell, Kenneth H. Mayer, and Chris Grasso; HAART Observational Medical Evaluation and Research: Robert S. Hogg, P. Richard Harrigan, Julio S. G. Montaner, Angela Cescon, and Tareq Ahmed; HIV Outpatient Study: Kate Buchacz, and John T. Brooks; HIV 
Research Network: Kelly A. Gebo and Richard D. Moore; Johns Hopkins HIV Clinical Cohort: Richard D. Moore; John T. Carey Special Immunology Unit Patient Care and Research Database, Case Western Reserve University: Benigno Rodriguez; Kaiser Permanente Mid-Atlantic States: Michael A. Horberg; Kaiser Permanente Northern California: Michael J. Silverberg; Longitudinal Study of Ocular Complications of AIDS: Jennifer E. Thorne; Multicenter Hemophilia Cohort Study-II: James J. Goedert; Multicenter AIDS Cohort Study: Lisa P. Jacobson and Gypsyamber D'Souza; Montreal Chest Institute Immunodeficiency Service Cohort: Marina B. Klein; Ontario HIV Treatment Network Cohort Study: Sean B. Rourke, Ann N. Burchell, and Anita R. Rachlis; Retrovirus Research Center, Bayamon Puerto Rico: Robert F. Hunter-Mellado and Angel M. Mayor; Southern Alberta Clinic Cohort: M. John Gill; Study of the Consequences of the Protease Inhibitor Era: Steven G. Deeks, and Jeffrey N. Martin; Study to Understand the Natural History of HIV/AIDS in the Era of Effective Therapy: Pragna Patel and John T. Brooks; University of Alabama at Birmingham 1917 Clinic Cohort: Michael S. Saag, Michael J. Mugavero, and James Willig; University of North Carolina at Chapel Hill HIV Clinic Cohort: Joseph J. Eron and Sonia Napravnik; University of Washington HIV Cohort: Mari M. Kitahata, Heidi M. Crane, and Daniel R. Drozd; Vanderbilt Comprehensive Care Clinic HIV Cohort: Timothy R. Sterling, David Haas, Peter Rebeiro, Sally Bebawy, and Megan Turner; Veterans Aging Cohort Study: Amy C. Justice, Robert Dubrow, and David Fiellin; Women's Interagency HIV Study: Stephen J. Gange and Kathryn Anastos. NAACCORD Study Administration: Executive Committee: Richard D. Moore, Michael S. Saag, Stephen J. Gange, Mari M. Kitahata, Keri N. Althoff, Rosemary G. McKaig, Amy C. Justice, and Aimee M. Freeman; Administrative Core: Richard D. Moore, Aimee M. Freeman, and Carol Lent; Data Management Core: Mari M. Kitahata, Stephen E. Van Rompaey, Heidi M. Crane, Daniel R. Drozd, Liz Morton, Justin McReynolds, and William B. Lober; Epidemiology and Biostatistics Core: Stephen J. Gange, Keri N. Althoff, Alison G. Abraham, Bryan Lau, Jinbing Zhang, Jerry Jing, Elizabeth Golub, Sharada Modur, Cherise Wong, Brenna Hogan, Weiqun Tong, Bin Liu, and Bin You. IeDEA-Southern Africa Steering Committee: Matthias Egger (co-PI), University of Bern, Switzerland; Mary-Ann Davies (co-PI), University of Cape Town, South Africa; Frank Tanser, Africa Centre for Health and Population Studies, University of Kwazulu-Natal, South Africa; Michael Vinikoor, Centre for Infectious Disease Research in Zambia; Eusebio Macete, Centro de Investigação em Saúde de Manhiça, Mozambique; Robin Wood, Desmond Tutu HIV Centre (Gugulethu and Masiphumelele clinics), South Africa; Andrew Boulle, Khayelitsha ART Programme and Médecins Sans Frontières, South Africa; Geoffrey Fatti, Kheth'Impilo Programme, South Africa; Sam Phiri, Lighthouse Trust Clinic, Malawi; Cleophas Chimbetete, Newlands Clinic, Zimbabwe; Kennedy Malisita, Queen Elizabeth Hospital, Malawi; Brian Eley, Red Cross War Memorial Children's Hospital and Department of Paediatrics and Child Health, University of Cape Town, South Africa; Jochen Ehmer, Solidarmed, Switzerland; Christiane Fritz, SolidarMed

\section{8 | www.jaids.com}

SMART Programme, Lesotho; Michael Hobbins, SolidarMed SMART Programme, Mozambique; Kamelia Kamenova, SolidarMed SMART Programme, Zimbabwe; Matthew Fox, Themba Lethu Clinic, South Africa; Hans Prozesky, Tygerberg Academic Hospital, South Africa; Karl Technau, Empilweni Clinic, Rahima Moosa Mother and Child Hospital, South Africa; Shobna Sawry, Harriet Shezi Children's Clinic, Chris Hani Baragwanath Academic Hospital, South Africa.

\section{REFERENCES}

1. UNAIDS. 90-90-90 An Ambitious Treatment Target to Help End the AIDS Epidemic. 2014. Available at: http://www.unaids.org/sites/default/ files/media asset/90-90-90_en 0.pdf. Accessed September 30, 2015.

2. World Health Organization. Consolidated Guidelines on the Use of Antiretroviral Drugs for Treatment and Preventing HIV Infection: Recommendations for a Public Health Approach. 2013. Available at: http://apps.who.int/iris/bitstream/10665/85321/1/9789241505727_eng. pdf. Accessed January 8, 2014.

3. IeDEA - The International Epidemiologic Databases to Evaluate AIDS network. 2015. Available at: http://www.iedea.org/. Accessed October 30,2015

4. Duda SN, Farr AM, Lindegren ML, et al. Characteristics and comprehensiveness of adult HIV care and treatment programmes in Asia-Pacific, sub-Saharan Africa and the Americas: results of a site assessment conducted by the International epidemiologic Databases to Evaluate AIDS (IeDEA) Collaboration. $J$ Int AIDS Soc. 2014;17:19045.

5. Althoff KN, Rebeiro PF, Hanna DB, et al. A picture is worth a thousand words: maps of HIV indicators to inform research, programs, and policy from NA-ACCORD and CCASAnet clinical cohorts. J Int AIDS Soc. 2016;19:20707

6. Joint United Nations Programme on HIV/AIDS. Global AIDS Update. Switzerland; 2016. Available at: http://www.unaids.org/sites/default/ files/media_asset/global-AIDS-update-2016_en.pdf.

7. Panel on Antiretroviral Guidelines for Adults and Adolescents. Guidelines for the Use of Antiretroviral Agents in HIV-1-Infected Adults and Adolescents. Department of Health and Human Services. Available at: https://aidsinfo.nih.gov/contentfiles/lvguidelines/adultandadolescentgl. pdf. Accessed April 27, 2016.

8. World Health Organization. Consolidated Guidelines on the Use of Antiretroviral Drugs for Treating and Preventing HIV Infection. Recommendations for a Public Health Approach. 2nd ed. 2016. Available at: http://www.who.int/hiv/pub/arv/arv-2016/en/. Accessed January 18, 2017.

9. Mberi MN, Kuonza LR, Dube NM, et al. Determinants of loss to followup in patients on antiretroviral treatment, South Africa, 2004-2012: a cohort study. BMC Health Serv Res. 2015;15:259.

10. Brinkhof MW, Dabis F, Myer L, et al. Early loss of HIV-infected patients on potent antiretroviral therapy programmes in lower-income countries. Bull World Health Organ. 2008;86:559-567.

11. World Health Organization. Guideline on When to Start Antiretroviral Therapy and on Pre-exposure Prophylaxis on HIV. 2015. Available at: http://apps.who.int/iris/bitstream/10665/186275/1/9789241509565_eng. pdf. Accessed January 22, 2016.

12. Lecher S, Ellenberger D, Kim AA, et al. Scale-up of HIV viral load monitoring - seven sub-Saharan African countries. MMWR Morb Mortal Wkly Rep. 2015;64:1287-1290.

13. Reynolds SJ, Nakigozi G, Newell K, et al. Failure of immunologic criteria to appropriately identify antiretroviral treatment failure in Uganda. AIDS. 2009;23:697-700.

14. Rawizza HE, Chaplin B, Meloni ST, et al. Immunologic criteria are poor predictors of virologic outcome: implications for HIV treatment monitoring in resource-limited settings. Clin Infect Dis. 2011;53:1283-1290.

15. Davies MA, Boulle A, Eley B, et al. Accuracy of immunological criteria for identifying virological failure in children on antiretroviral therapythe IeDEA Southern Africa Collaboration. Trop Med Int Health. 2011; $16: 1367-1371$.

16. Hoffmann CJ, Maritz J, van Zyl GU. CD4 count-based failure criteria combined with viral load monitoring may trigger worse switch decisions than viral load monitoring alone. Trop Med Int Health. 2016;21:219223.

Copyright (C) 2017 Wolters Kluwer Health, Inc. All rights reserved. 
17. Cozzi-Lepri A, Paredes, Phillips AN, et al. The rate of accumulation of nonnucleoside reverse transcriptase inhibitor (NNRTI) resistance in patients kept on a virologically failing regimen containing an NNRTI*. HIV Med. 2012;13:62-72.

18. Zhao Y, Mu W, Harwell J, et al. Drug resistance profiles among HIV-1infected children experiencing delayed switch and 12-month efficacy after using second-line antiretroviral therapy: an observational cohort study in rural China. J Acquir Immune Defic Syndr. 2011;58:47-53.

19. Mekuria LA, Nieuwkerk PT, Yalew AW, et al. High level of virological suppression among HIV-infected adults receiving combination antiretroviral therapy in Addis Ababa, Ethiopia. Antivir Ther. 2016;21:385-396.

20. Cornell M, Lessells R, Fox MP, et al. Mortality among adults transferred and lost to follow-up from antiretroviral therapy programmes in South Africa: a multicenter cohort study. J Acquir Immune Defic Syndr. 2014; 67:e67-e75.

21. Braitstein P, Songok J, Vreeman RC, et al. "Wamepotea" (they have become lost): outcomes of HIV-positive and HIV-exposed children lost to follow-up from a large HIV treatment program in western Kenya. $J$ Acquir Immune Defic Syndr. 2011;57:e40-46.

22. McManus H, Petoumenos K, Brown K, et al. Loss to follow-up in the Australian HIV observational database. Antivir Ther. 2015;20:731-41.

23. Zhou J, Kumarasamy N, Ditangco R, et al. The TREAT Asia HIV Observational Database: baseline and retrospective data. $J$ Acquir Immune Defic Syndr. 2005;38:174-179.

24. IeDEA Pediatric Working Group. A survey of paediatric HIV programmatic and clinical management practices in Asia and sub-Saharan Africa-the International epidemiologic Databases to Evaluate AIDS (IeDEA). J Int AIDS Soc. 2013;16:17998.

25. Shet A, Neogi U, Kumarasamy N, et al. Virological efficacy with firstline antiretroviral treatment in India: predictors of viral failure and evidence of viral resuppression. Trop Med Int Health. 2015;20:14621472.

26. Huang $\mathrm{P}$, Tan $\mathrm{J}$, Ma W, et al. Outcomes of antiretroviral treatment in HIV-infected adults: a dynamic and observational cohort study in Shenzhen, China, 2003-2014. BMJ Open. 2015;5:e07508.
27. Collazos J, Asensi V, Carton JA; Grupo Espanol para el Estudio Multifactorial de la A. Association of HIV transmission categories with sociodemographic, viroimmunological and clinical parameters of HIVinfected patients. Epidemiol Infect. 2010;138:1016-1024.

28. Graham SM, Mugo P, Gichuru E, et al. Adherence to antiretroviral therapy and clinical outcomes among young adults reporting high-risk sexual behavior, including men who have sex with men, in coastal Kenya. AIDS Behav. 2013;17:1255-1265.

29. Jiamsakul A, Kumarasamy N, Ditangco R, et al. Factors associated with suboptimal adherence to antiretroviral therapy in Asia. J Int AIDS Soc. 2014; 17:18911.

30. Ortego C, Huedo-Medina TB, Santos P, et al. Sex differences in adherence to highly active antiretroviral therapy: a meta-analysis. AIDS Care. 2012;24:1519-1534.

31. Puskas CM, Kaida A, Miller CL, et al. The adherence gap: a longitudinal examination of men's and women's antiretroviral therapy adherence in British Columbia, 2000-2014. AIDS. 2017;31:827-833.

32. Shearer WT, Quinn TC, LaRussa P, et al. Viral load and disease progression in infants infected with human immunodeficiency virus type 1. Women and Infants Transmission Study Group. N Engl J Med. 1997; 336:1337-1342.

33. Davies MA, Moultrie H, Eley B, et al. Virologic failure and second-line antiretroviral therapy in children in South Africa-the IeDEA Southern Africa collaboration. J Acquir Immune Defic Syndr. 2011;56:270-278.

34. Walker AS, Doerholt K, Sharland M, et al; Collaborative HIVPSSC Response to highly active antiretroviral therapy varies with age: the UK and Ireland Collaborative HIV Paediatric Study. AIDS. 2004;18:19151924.

35. Glass TR, Sterne JA, Schneider MP, et al. Self-reported nonadherence to antiretroviral therapy as a predictor of viral failure and mortality. AIDS 2015;29:2195-2200.

36. Teasdale CA, Abrams EJ, Coovadia A, et al. Adherence and viral suppression among infants and young children initiating protease inhibitor-based antiretroviral therapy. Pediatr Infect Dis J. 2013;32: 489-494. 